\title{
Identification of material parameters to predict Single Point Incremental Forming forces
}

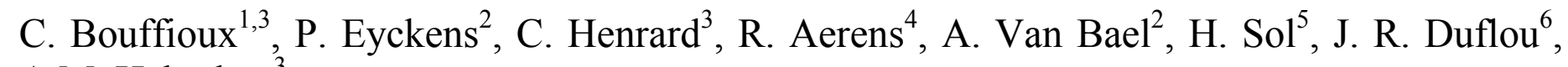
A.M. Habraken ${ }^{3}$

${ }^{1}$ Department MEMC, Vrije Universiteit Brussel, Pleinlaan 2, B-1050 Brussels, Belgium, currently in 3

${ }^{2}$ Department MTM, Katholieke Universiteit Leuven, Kasteelpark Arenberg 44, B-3001 Heverlee, Belgium http://www.mtm.kuleuven.be_philip.eyckens@mtm.kuleuven.be;Albert.VanBael@mtm.kuleuven.be

${ }^{3}$ Department ArGEnCo, Université de Liège, Chemin des Chevreuils 1, B-4000 Liège, Belgium. http://www.argenco.ulg.ac.be_Anne.Habraken;Christophe.Henrard; Chantal.Bouffioux@ulg.ac.be

${ }^{4}$ SIRRIS, Celestijnenlaan 300C, B-3001 Heverlee, Belgium.

http://www.sirris.be Richard.Aerens@sirris.be

${ }^{5}$ Department MEMC, Vrije Universiteit Brussel, Pleinlaan 2, B-1050 Brussels, Belgium. http://wwwtw.vub.ac.be/memcrhugos@vub.ac.be

${ }^{6}$ Department PMA, Katholieke Universiteit Leuven, Celestijnenlaan 300B, B-3001 Heverlee, Belgium http://www.mech.kuleuven.be/pma joost.duflou@mech.kuleuven.ac.be

ABSTRACT: The purpose of this article is to develop an inverse method for adjusting the material parameters for single point incremental forming (SPIF). The main idea consists in FEM simulations of simple tests involving the SPIF specificities (the "line test") performed on the machine used for the process itself. This approach decreases the equipment cost. It has the advantage that the material parameters are fitted for heterogeneous stress and strain fields close to the ones occurring during the actual process. A first set of material parameters, adjusted for the aluminum alloy AA3103 with classical tests (tensile and cyclic shear tests), is compared with parameters adjusted by the line test. It is shown that the chosen tests and the strain state level have an important impact on the adjusted material data and on the accuracy of the tool force prediction reached during the SPIF process.

Key words: Sheet metal forming, Inverse method, FEM simulations, Aluminum alloy AA3103, SPIF process

\section{INTRODUCTION}

Single Point Incremental Forming (SPIF) is a new sheet metal forming process adapted to both rapid prototyping and small batch production at low cost. A clamped sheet is deformed by a spherical tool following a specific tool path defining the final required shape without costly dies. A wide variety of shapes can be made [1].

Accuracy of the FEM simulations of this process depends both on the constitutive law and the identification of the material parameters. A simple isotropic hardening model is not sufficient to provide an accurate force prediction [2].

A specific inverse method has been studied to provide the materials parameters using the results of experiments performed directly on a SPIF machine. The material is an annealed aluminium alloy AA3103-O. A first set of material parameters, adjusted by the inverse method using classical tests (tensile and cyclic shear tests) is compared with a new set of data adjusted by both a tensile test and an indent test performed with the actual SPIF equipment.

To validate the material data set, the evolution of the predicted tool force during a line test is compared with the experimental results. 


\section{MATERIAL LAW}

\subsection{Description of the constitutive law}

The elastic range is described by Hooke's law where the Young's modulus E= $72600 \mathrm{MPa}$ and the Poisson's ratio $v=0.36$ were identified using an acoustic method.

The plastic part is described by Hill'48 law:

$\mathrm{F}_{\mathrm{HILL}}(\underline{\sigma})=\frac{1}{2}\left[(\mathrm{H}+\mathrm{G}) \sigma_{11}^{2}+(\mathrm{H}+\mathrm{F}) \sigma_{22}^{2}-2 \mathrm{H} \sigma_{11} \sigma_{22}+2 \mathrm{~N} \sigma_{12}^{2}\right]-\sigma_{\mathrm{F}}^{2}=0$

where the parameters $\mathrm{F}, \mathrm{G}, \mathrm{H}, \mathrm{N}$ and the yield stress $\sigma_{\mathrm{F}}$ are identified using a tensile test in the rolling direction.

The hardening equation is described by the Swift law (2):

$\sigma_{\mathrm{F}}=\mathrm{K}\left(\varepsilon_{0}+\varepsilon^{\mathrm{p}}\right)^{\mathrm{n}}$

where $\varepsilon^{\mathrm{p}}$ is the plastic strain and $\mathrm{K}, \varepsilon_{0}$ and $\mathrm{n}$ are the material parameters.

If kinematic hardening is used, the stress tensor in (1) is replaced by $\underline{\sigma}-\underline{X}$ where $\underline{X}$ is the backstress.

The material is assumed to have the same behaviour in tension and in compression at the beginning of the process, so no initial back-stress is defined.

The kinematic hardening can be described by two formulations: the Amstrong-Frederick:

$\underline{\dot{X}}=\mathrm{C}_{\mathrm{X}}\left(\mathrm{X}_{\mathrm{SAT}} \cdot \underline{\dot{\varepsilon}^{\mathrm{p}}}-\dot{\bar{\varepsilon}}^{\mathrm{p}} \cdot \underline{\mathrm{X}}\right)$

with $C_{X}$ the saturation rate, $X_{S A T}$ the saturation value of kinematic hardening and $\dot{\bar{\varepsilon}}^{\mathrm{p}}$ the anisotropic equivalent plastic strain rate;

or the Ziegler hardening equations:

$\underline{\dot{X}}=\mathrm{C}_{\mathrm{A}} \frac{1}{\sigma_{\mathrm{F}}}(\underline{\sigma}-\underline{\mathrm{X}}) \cdot \dot{\bar{\varepsilon}}^{\mathrm{p}}-\mathrm{G}_{\mathrm{A}} \cdot \underline{\mathrm{X}} \cdot \dot{\bar{\varepsilon}}^{\mathrm{p}}$

with $\mathrm{C}_{\mathrm{A}}$ the initial kinematic hardening modulus and $\mathrm{G}_{\mathrm{A}}$ the rate at which the kinematic hardening modulus decreases with increasing plastic deformation.

\section{DATA ADJUSTED BY CLASSICAL TESTS}

\subsection{Parameters identification}

The first identification method consists in performing tensile tests, monotonic shear tests and
Bauschinger tests at two different levels of pre-strain (10 and 30\%). The material parameters, adjusted by the inverse method, give a good correlation between the experiments and simulation results. The isotropic Swift law (2) is fitted with the parameters defined in table 1 but such tests do not indicate clearly whether there is or not a kinematic hardening.

Table 1. Data adjusted by classical tests (Units: N, mm)

\begin{tabular}{llll}
\hline & $\begin{array}{l}\text { Yield surface } \\
\text { coefficients }\end{array}$ & $\begin{array}{l}\text { Swift } \\
\text { parameters }\end{array}$ & $\begin{array}{l}\text { Back-stress } \\
\text { data }\end{array}$ \\
\hline HILL classic & $\mathrm{F}=1.224$ & $\mathrm{~K}=183$ & $\mathrm{C}_{\mathrm{x}}=0$ \\
& $\mathrm{G}=1.193$ & $\varepsilon_{0}=0.00057$ & $\mathrm{X}_{\text {sat }}=0$ \\
& $\mathrm{H}=0.8067$ & $\mathrm{n}=0.229$ & \\
& $\mathrm{~N}=\mathrm{L}=\mathrm{M}=4.06$ & & \\
\hline
\end{tabular}

\subsection{Parameters validation by the line test}

A line test performed with the SPIF machine is used to verify the accuracy of the fitted data: a square plate with a thickness of $1.5 \mathrm{~mm}$ is clamped along its edges (Figure 1). The spherical tool radius is $5 \mathrm{~mm}$. The tests are performed three times and the bolts of the frame are tightened using the same torque to ensure the reproducibility of the results.
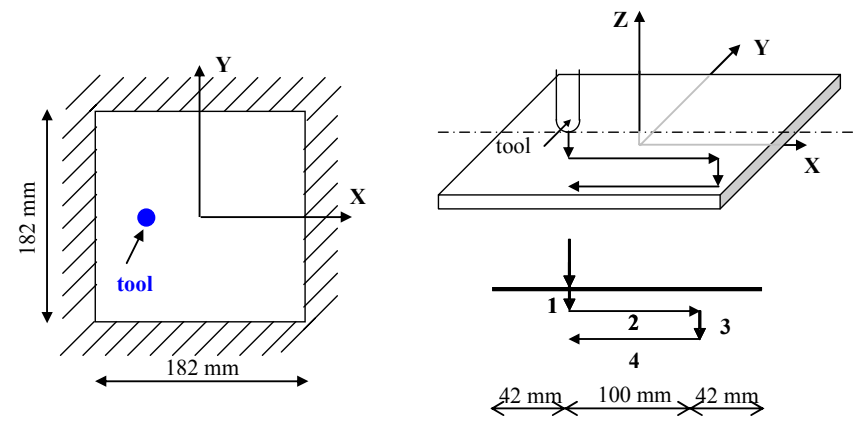

Fig. 1. Description of the line test

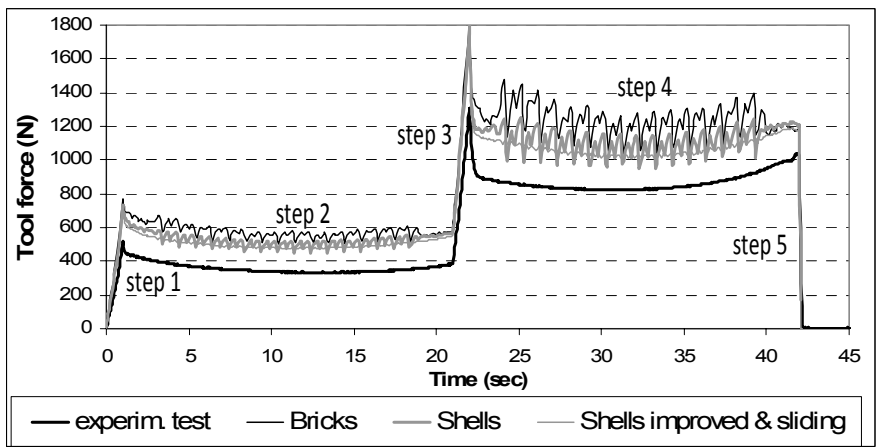

Fig. 2. Evolution of tool force during the line test (Lagamine)

The displacement of the tool is composed of five steps with an initial position tangent to the surface of the plate: a first indent of $5 \mathrm{~mm}$ (step 1), a line movement at the same depth along the $\mathrm{X}$ axis (step 2 ), then a second indent up to the depth of $10 \mathrm{~mm}$ (step 3) followed by a line at the same depth along the $\mathrm{X}$ axis (step 4) and the unloading (step5). 
In the FEM simulations, the nodes along the edges are fixed. The tool force is computed by the static implicit strategy. The Coulomb's friction coefficient of 0.05 is applied between the tool and the sheet. The mesh is adjusted to limit the number of elements while keeping accuracy. Two element types are tested: brick with three layers along the thickness and shell elements.

Figure 2 shows that the numerical force evolution of the tool is higher than the experimental one.

\subsection{Discussion}

The oscillations in the numerical model are due to the contact elements. The sensitivity analysis shows that, unlike the bricks, the shell elements predict the same tool force for both a coarse and a very fine mesh. Those elements are also suitable for the inverse method since the computation time is lower than when using the brick elements.

The effects of the geometry inaccuracy of the plate (dimension, thickness, flatness) and the tool (initial position, diameter), of the machine elasticity, of the force measurement, of the FEM parameters (elements stiffness, number of layers for the bricks), of the material data values and of the friction coefficient have been examined. Alone or combined, none of these parameters can explain such a gap between predicted and experimental forces.

\subsection{Sliding sensitivity}

Previous experimental tests performed on a plate with a thickness of $1.2 \mathrm{~mm}$ showed that such a test is highly sensitive to sliding at the edges. The force was up to $35 \%$ lower when the bolts were tightened without a sufficient torque. A numerical sensitivity analysis showed that a small sliding of about 0.08 $\mathrm{mm}$ of the edges could decrease the tool force of $16 \%$.

Then, for the experiments in figure 2 , the careful clamping of the frame provides an average sliding of only $0.0125 \mathrm{~mm}$.

A new model with springs regularly distributed along the edges allowing translation of the boundaries is combined with all of the imperfections inducing a tool force reduction. The spring stiffness is fitted to reproduce the same sliding as in the real process. The tool force of this model, called: "Shell improved \& sliding" in figure 2 , shows a small force reduction. In conclusion, the simulation inaccuracy cannot be explained by these performed investigations.

\section{DATA ADJUSTED BY INDENT TEST}

\subsection{Parameters identification}

The new identification method consists in fitting material data using both a classical tensile test and an indent test corresponding to the first step of the line test described in section 3.2. The latter test contains heterogeneous stress and strain fields with tension, compression and shear stresses. The obtained material parameters are expected to be more accurate, since the deformation fields are much closer to those occurring in the SPIF process [3].

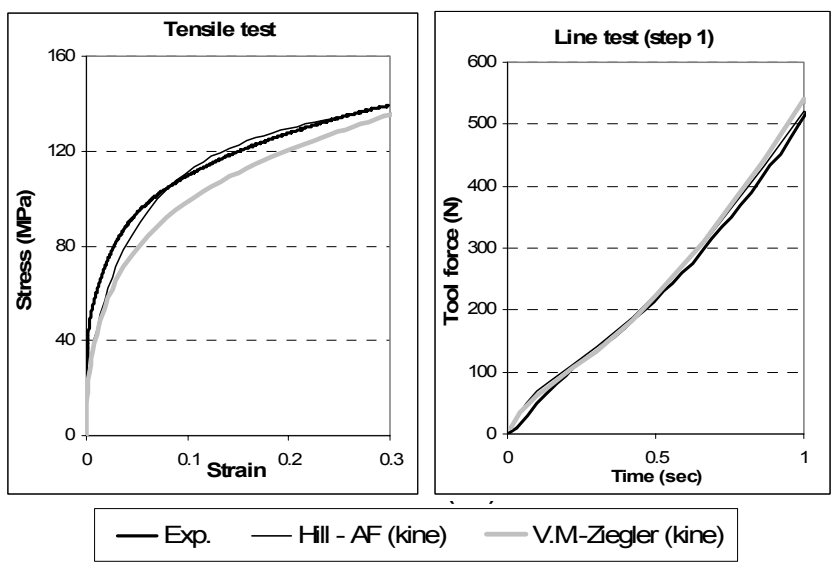

Fig. 3. Tensile test and the step 1 of the line test for the different material models and the experiment

Table 2. Data adjusted (Units: N, mm)

\begin{tabular}{llll}
\hline & $\begin{array}{l}\text { Yield surface } \\
\text { coefficients }\end{array}$ & $\begin{array}{l}\text { Swift } \\
\text { parameters }\end{array}$ & $\begin{array}{l}\text { Back stress } \\
\text { data }\end{array}$ \\
\hline HILL - & $\mathrm{F}=1.224$ & $\mathrm{~K}=120.2$ & $\mathrm{C}_{\mathrm{x}}=29.7$ \\
AF (kine) & $\mathrm{G}=1.193$ & $\begin{array}{l}\varepsilon_{0}=0.000926 \\
\mathrm{H}=0.8067\end{array}$ & $\mathrm{n}=0.288$ \\
& $\mathrm{X}$ sat $=26$ \\
& $\mathrm{~N}=\mathrm{L}=\mathrm{M}=4.06$ & & \\
\hline Von Mises - & $\mathrm{F}=\mathrm{G}=\mathrm{H}=1$ & $\mathrm{~K}=175.0$ & $\mathrm{C}_{\mathrm{A}}=800$ \\
Ziegler (kine) & $\mathrm{N}=\mathrm{L}=\mathrm{M}=3$ & $\begin{array}{l}\varepsilon_{0}=0.00015 \\
\mathrm{n}=0.328\end{array}$ & $\mathrm{G}_{\mathrm{A}}=45.9$ \\
\hline
\end{tabular}

Figure 3 shows a poor fitting in tension but a good force prediction in the indent test.

Table 2 defines the parameter values fitted for both hardening model described in section 2.

The Ziegler hardening is coupled with Von Mises yield locus to allow comparison with Abaqus.

Unlike the first investigation, a kinematic hardening is predicted in this case.

\subsection{Parameters verification on experiments}

The two material models are used to simulate the 
line test with brick elements (the kinematic hardening is currently not available with shells). Figure 4 shows a quite good correlation between the levels of predicted and measured tool force, especially for the first two steps of the line test.

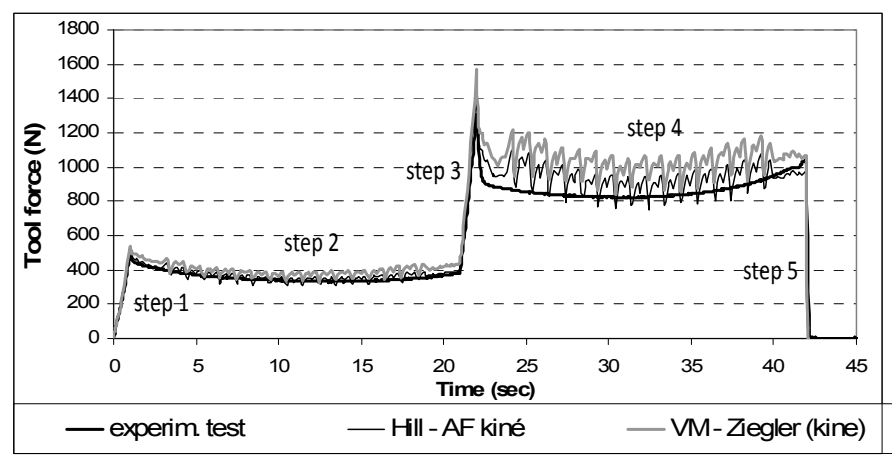

Fig. 4. Evolution of tool force during the line test (Lagamine)

The comparison between Lagamine (home-made code by the $\mathrm{MS}^{2} \mathrm{~F}$ - ARGENCO department) and implicit Abaqus FEM codes shows that the parameters identification depends on the stiffness of the brick elements. The tool force with Abaqus with reduced-integration elements and an artificial Hourglass stiffness of 1.33MPa gives the same level of force prediction than Lagamine for both tensile and line tests.

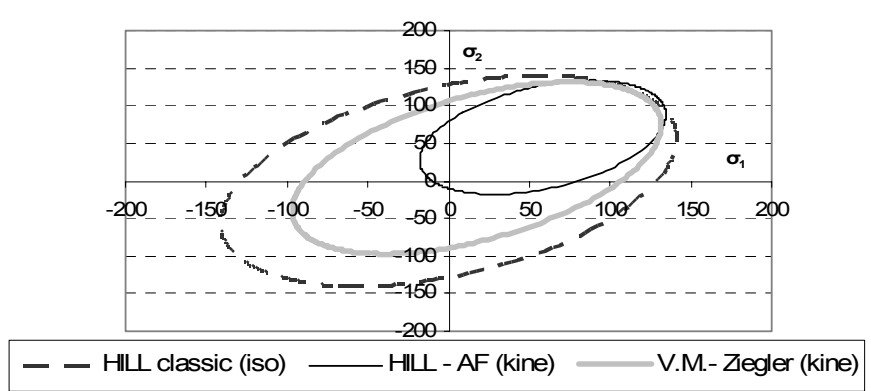

Fig. 5. Yield loci in principal stress direction at the end of the step 1 of the line test for the different material models

Figure 5 shows the yield locus shapes at the end of the indent test in an element below the tool, for the three different material models (see tables 1 and 2).

\subsection{Discussion}

Figure 5 shows that data fitted by the indent test induce a kinematic hardening and a modification of the yield locus in compression but almost no adjustment in tension.

Our model did not introduce an initial back-stress as the annealed material is supposed to have the same initial behaviour in tension and compression. This assumption could be wrong but should require a physical explanation. A simple bending test has been performed to check it [4] but not fully analysed yet. The coupling of an initial back-stress and a kinematic hardening adapted to shell elements could be the best way to fit the right initial yield locus and its evolution.

The shell elements having accurate results and a short computation time should be more suitable to the inverse method.

As a next step, the indentation depth can be increased or the whole line test can be used to a better data fitting.

\section{CONCLUSIONS}

The identification method of material data is far from being trivial. The strain state reached during the chosen tests have an important impact on the adjusted material data and on the accuracy of the tool force prediction during the process.

The classical method used to identify material data by a combination of tensile and cyclic shear tests seems not adapted to the SPIF process on the aluminium alloy AA3103.

Our new approach based on tests inducing stress and strain fields, similar to those present in the real process, predicts a better tool force.

\section{ACKNOWLEDGEMENTS}

The authors of this article would like to thank the Institute for the Promotion of Innovation by Science and Technology in Flanders (IWT) and the Belgian Federal Science Policy Office (Contract P6-24) for their financial support.

As Research Director, A.M. Habraken would like to thank the Fund for Scientific Research (FNRS, Belgium) for its support.

\section{REFERENCES}

1. J. Jeswiet, F. Micari, G. Hirt, A. Bramley, J. R. Duflou, J. Allwood, Asymmetric Single Point Incremental Forming of Sheet Metal, CIRP Annals 2005, Vol. 54/2, Technische Rundschau, Switzerland, pp. 623-649.

2. P. Flores, L. Duchêne, C. Bouffioux, T.Lelotte, C. Henrard, N. Pernin, A. Van Bael, S. He, J. Duflou, A.M.Habraken, Model Identification and FE Simulations: Effect of Different Yield Loci and Hardening Laws in Sheet Forming, Int Journal of Plasticity, 23/3 , 2007, pp. 420-449.

3. J.R. Duflou, J. Verbert, B. Belkassem, J. Gu, H. Sol, C. Henrard, A.M. Habraken, Process Window Enhancement for Single Point Incremental Forming through Multi-Step Toolpaths, to appear.

4. R. Aerens, S. Masselis, Le pliage en l'air, Sirris report, MC 110, march 2000. 